\title{
Geometric Modeling for Visualization of Technological Processes from a Text Instruction to an Interactive Simulator
}

\author{
Tatiana Fedorova, Alexander Filinskih, Olga Sosnina \\ Nizhny Novgorod State Technical University n.a. R.E. Alekseev, \\ Nizhny Novgorod Russia
}

\begin{abstract}
The present article examines different forms of presentation of training materials in the visualization of technological processes. As example instruction for measuring the parameters of receiving microwave modules was used. The development of text instruction, graphic instruction, multimedia video (using virtual models of devices developed in specialized software), an interactive multimedia video and an interactive simulator are described. The article describes the stages and features of the development of each type of materials. Screenshots of the practical implementation of each type of instruction are presented. People, depending on the characteristics of the perception of information, are divided into three types: visuals, audials and kinesthetics. Particular attention in this article is paid to the effectiveness of the use of each type of training material for people with a specific type of information perception. The article provides a comparative analysis of training instructions for the duration of development.
\end{abstract}

Keywords: Visualization of Technological Processes, Forms for the Presentation of Training Materials, Development of Text Instructions, Development of Graphic Instructions, Development of a Multimedia Video, Development of an Interactive Multimedia Video, Development of an Interactive Simulator.

\section{Introduction}

In our days one of the major problems at enterprises (associated with the release of science-intensive products) is the selection and training of staff to work on modern complex equipment. The release of new products is also due to the implementation of new technological processes for the development and testing of new equipment. In this regard, particular attention at the enterprises began to be paid to the training of staff.

Copyright (C) 2020 for this paper by its authors. Use permitted under Creative Commons License Attribution 4.0 International (CC BY 4.0). 
The implementation of information technologies at enterprises is due to the fact that its allow to simplify and speed up many production processes $[1,2]$. One of the areas of application of information systems and technologies is training staff to work with equipment, including expensive ones.

The purpose of this research is to identify the features of the development of educational multimedia materials in the visualization of technological processes.

This topic is relevant, due to the fact that at this moment in the Russian market enterprises have a need in visualization of technological processes. This need is due to the fact that when you are working with expensive equipment due to insufficient awareness of staff about the principles of its operation, breakdowns occur. Breakdowns are leading to additional costs for repairs. The way out of this situation is to provide the staff with quality training materials. [3]

To achieve this goal, it is necessary to solve a few tasks:

- to analyze the forms of presentation of training materials;

- to consider the features of the implementation of each form of presentation of training materials in practice, to identify the features.

\section{Analysis of the forms of presentation of training materials}

The first step is choosing the form of presentation of training materials. An important factor is to understand how people perceive information.

A person, based on the analysis of the impact on the senses (vision, hearing, smell, taste and touch), gets a certain idea about phenomena, objects. According to the way a person perceives information, we could divide it into: visual, sound, tactile, gustatory and olfactory. According to the way of presentation information, we could divide it into: text, numerical, sound and graphic. [4]

At the same time, the same information received in a certain way is perceived by each person differently. According to the characteristics of the perception of information, people are usually divided into 3 main types: visuals, audials and kinesthetics. For each type of people different types of information (by the way of perception and by the way of presentation) will be the most preferable.

For visuals, the visual information processing system is dominant. They better remember the visual component, namely: shapes, locations and colors.

For audials, the auditory system of information processing is dominant. They perceive sounds, melodies, tone, loudness, timbre, purity to a greater extent.

For kinesthetics, sensory information is dominant: touch, taste, smell, texture, temperature, and interactivity. [5]

Thus, among the possible forms of presentation of educational materials, the following can be distinguished: text instructions, graphic instructions, multimedia videos, interactive multimedia videos, interactive programs.

The following sections of this research contain the stages and features of development these forms of representation and their effectiveness when applied to training 
visuals, audials and kinesthetics. All training materials were developed at the topic "Measurement of parameters of receiving microwave modules".

When analyzing the effectiveness of using each type of instruction for a person with a certain type of perception, important factors are: the degree of visibility of information (assessment of its visual component - diagrams, illustrations, 3D models), the presence of a sound component, interactivity. Another important factor is the comparison of the development time of a certain form of training materials.

\section{Text instruction}

In the standard sense, a text instruction is a text divided into successive stages, each of which must be performed to achieve a specific goal. The instruction should not allow ambiguity, but should briefly and succinctly describe each step. [6]

A text editor Microsoft Office Word is suitable for developing instructions. It is widespread among users and has all necessary functions.

In the course of this study, the text instruction was developed on the basis of the existing guidelines for measuring the parameters of receiving microwave modules. The design was improved and the correct logical sequence of points was restored.

The main stages of the development of text instructions:

1. analysis of the existing instructions (checking the sequence of presentation, the consistency of division into sections, compliance of the design with the requirements);

2. design of the title page;

3. correction of identified deficiencies.

If it is not possible to base on existing guidelines, then additional time will need to be allocated to the logical division of the process requiring description, based on the implementation of this process in practice.

\section{$4 \quad$ Graphic instruction}

A graphic instruction differs from a text one by an abundance of illustrations, which make it possible to more clearly represent the actions and objects described in it. Therefore, the basis for this instruction can be a developed text instruction, which must be provided with visual elements and illustrations to facilitate the process of information perception.

The vector graphic editor Adobe Illustrator is suitable for the development of graphic instructions.

The development of graphic instructions (see Fig. 1) can be divided into a few stages:

1. writing the text;

2. choice of colors;

3. choice of fonts;

4. composition of content on the layout;

5. drawing illustrations; 
6. adjustment of the layout in accordance with the developed illustrations;

7. prepress (if required).

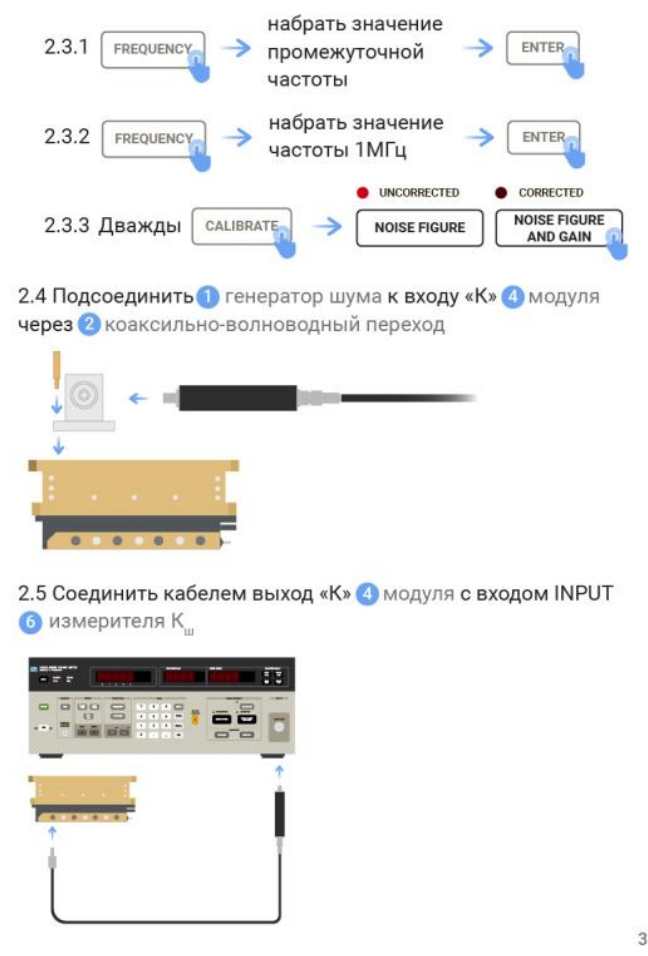

Fig. 1. The page from the graphic instruction

\section{$5 \quad$ Multimedia video}

The multimedia video allows you to present technological processes in a more visual form. Also you can provide them with sound accompaniment, which ensures a more efficient absorption of information by the audials.

For the greatest clarity of the processes described in the instructions, the use of virtual models of devices in the video may be a suitable solution. Virtual models make possible a closer and more detailed demonstration, including of hard-to-reach details of devices. [7-9]

The development of models and their animation was carried out in the 3ds MAX software environment. When creating models of devices and environments, the techniques of polygonal and spline modeling were used [10-12]. The process of virtual modeling of devices consists of several stages:

1. creation of a model of the device, according to the references; 
Geometric Modeling for Visualization of Technological Processes from a Text Instruction... 5

2. setting up lighting;

3. creation of materials and drawing of the corresponding textures in graphic editors;

4. render setup (in this work, the Mental ray visualizer was used).

When the models are created, you can start working on the animation. During the creation of the animation, the most difficult thing was to implement the realistic movement of the wires. To solve this problem, the Bones system was used with the attached Physique modifier. It made possible to move and bend the wires without changing their length.

The developed animation is rendered into avi videos. On the basis of these videos the final multimedia video is developed. The development of a multimedia video is divided into a few stages. Appropriate software must be used at each stage (see Fig. 2). A screenshot from the developed video is presented below (see Fig. 3).
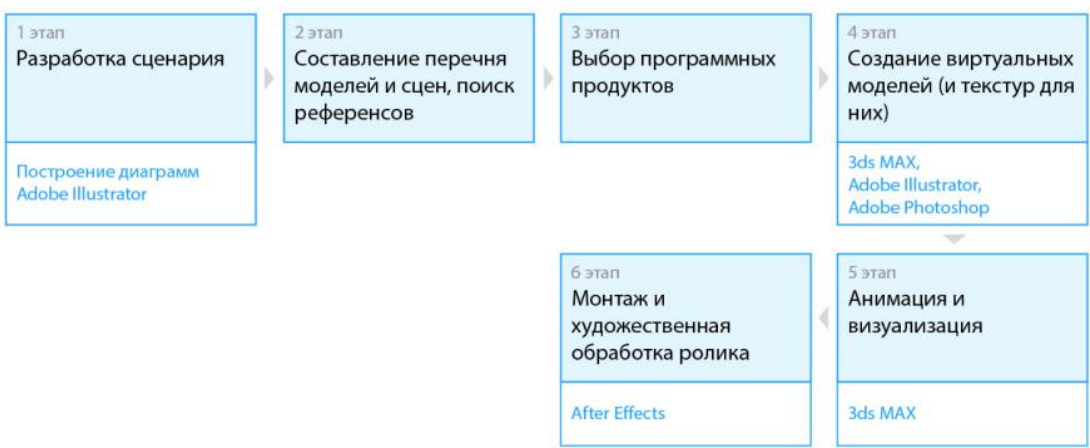

Fig. 2. Stages of developing a multimedia video

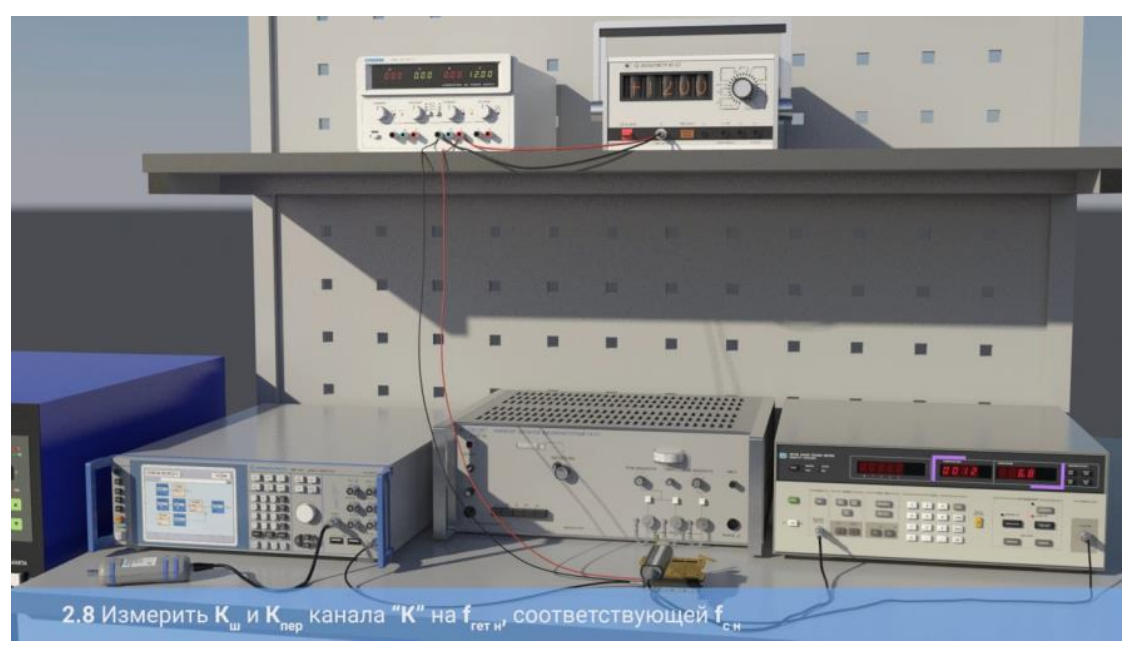

Fig. 3. The shot from the multimedia video 


\section{Interactive multimedia video}

The introduction of interactive elements into a multimedia video allows you to increase user involvement in the learning process.

An interactive multimedia video can be developed on the basis of a multimedia video by introducing interactive elements that allow you to move between the semantic parts of the instruction more flexibly. The video is divided into separate fragments, which are interconnected by hyperlinks. All of this can be done through the use of technologies such as: HTML, CSS and JavaScript.

Thus, the development of the interactive video was carried out in accordance with the following stages:

5. division of the developed multimedia video into short semantic parts;

6. development of a diagram of the relationship between parts, including the navigation;

7. interface design;

8. creation of the necessary illustrations in a graphic editor;

9. software implementation of the resulting concept (in this case, using HTML, CSS and JavaScript).

A screenshot from the final interactive multimedia video is shown below (see Fig. 4).

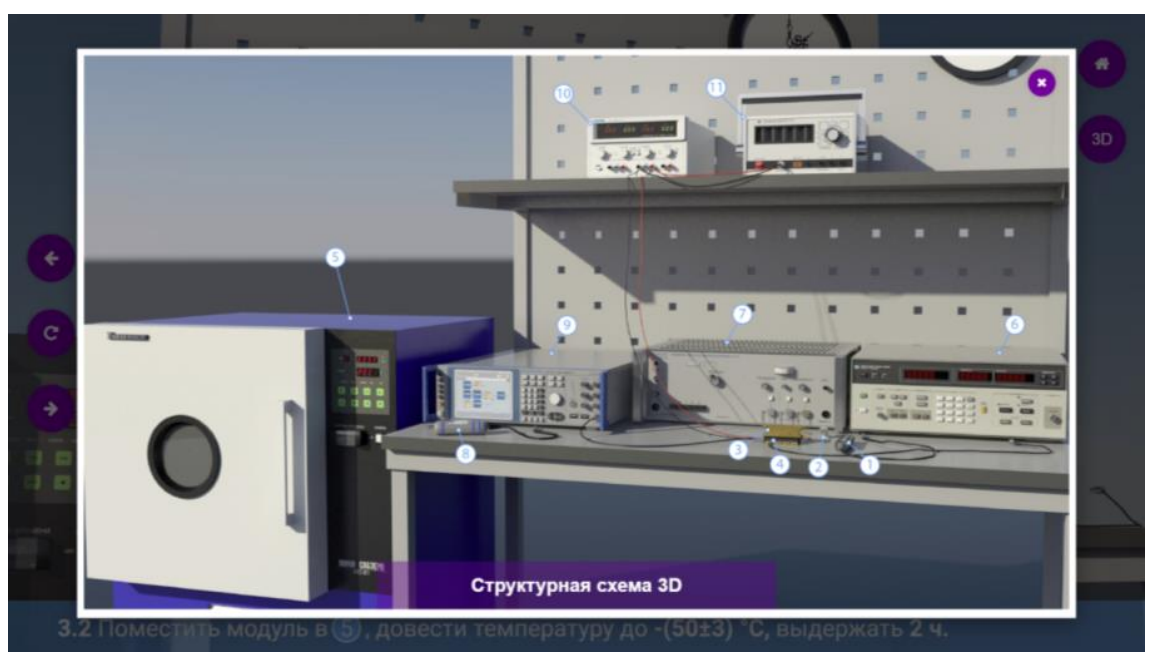

Fig. 4. Screenshot from an interactive multimedia video

\section{$7 \quad$ Interactive simulator}

The interactive simulator allows the user to be more involved in the educational process. The simulator gives him the opportunity to personally try to carry out the actions 
that he needs in the process of measuring the parameters of the receiving microwave modules.

The purpose of the interactive simulator: to teach the user to assemble a workplace according to a structural diagram.

In this simulator, the user can interact with virtual models of devices using the mouse. Its task is to connect all devices according to the provided structural diagram.

An interactive simulator is being developed using virtual models already developed in the process of creating a multimedia video.

The development of an interactive simulator can be divided into a few stages:

1. script development;

2. creation of interactive layouts;

3. preparation of $3 \mathrm{~d}$ models;

4. export of $3 \mathrm{~d}$ models;

5. development of mechanics (including scripting) and interface;

6. tests and making corrections, according to the results obtained;

7. building of a program.

Several scenes must be provided in the simulator: main menu, help information, block diagram, assembly mode of the structural diagram. In addition to the scenes, you will need a number of pop-ups. A diagram was developed to visualize the relationship between them (see Fig. 5).

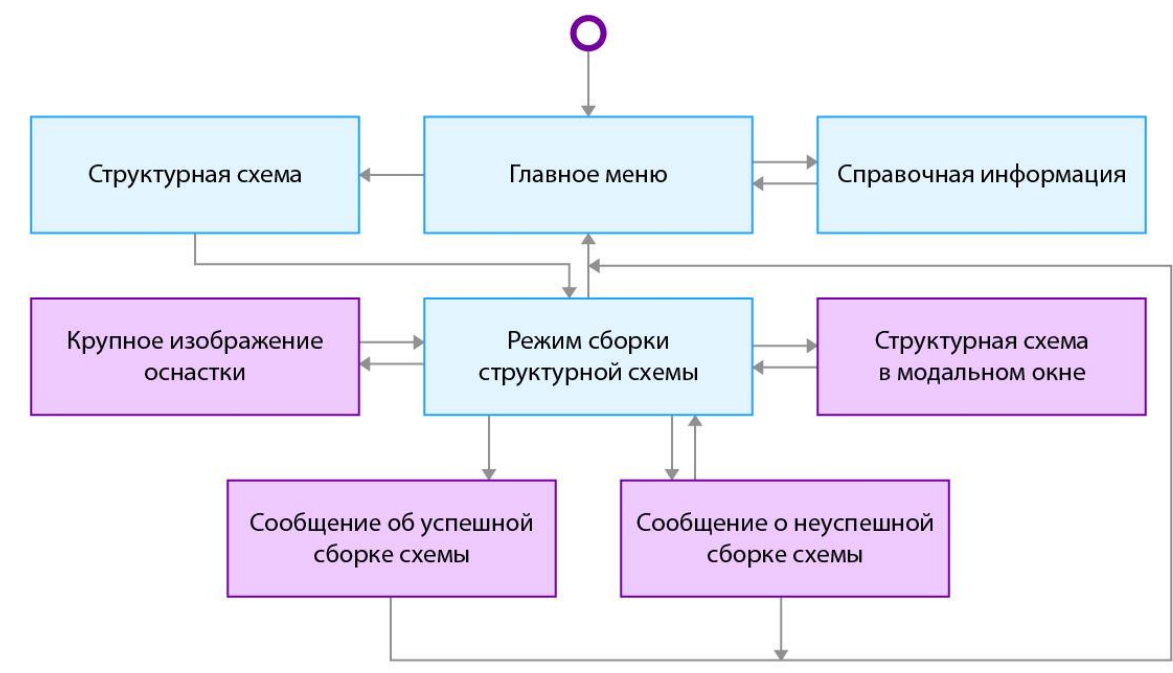

Fig. 5. The connection between scenes and modal windows

Screenshots from the developed simulator are presented below (see Fig. 6, Fig. 7, Fig. 8). 
8 T. Fedorova, A. Filinskih, O. Sosnina

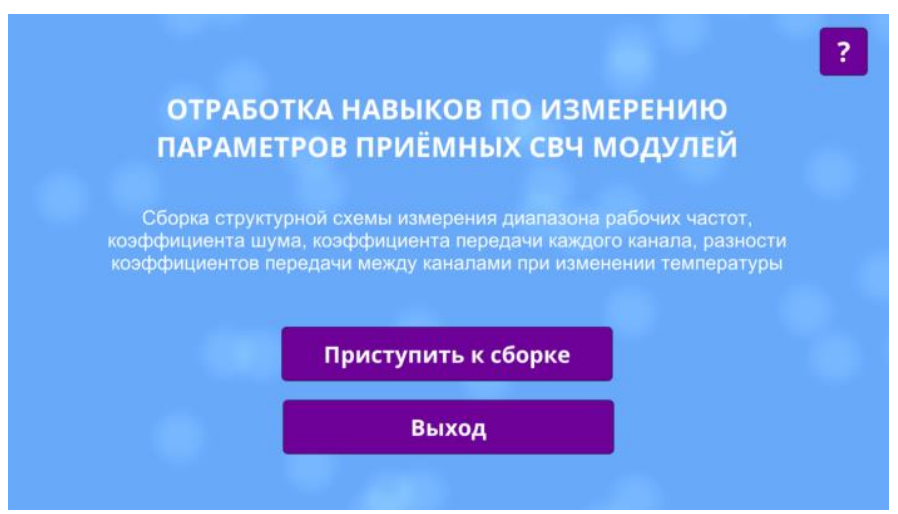

Fig. 6. Main menu

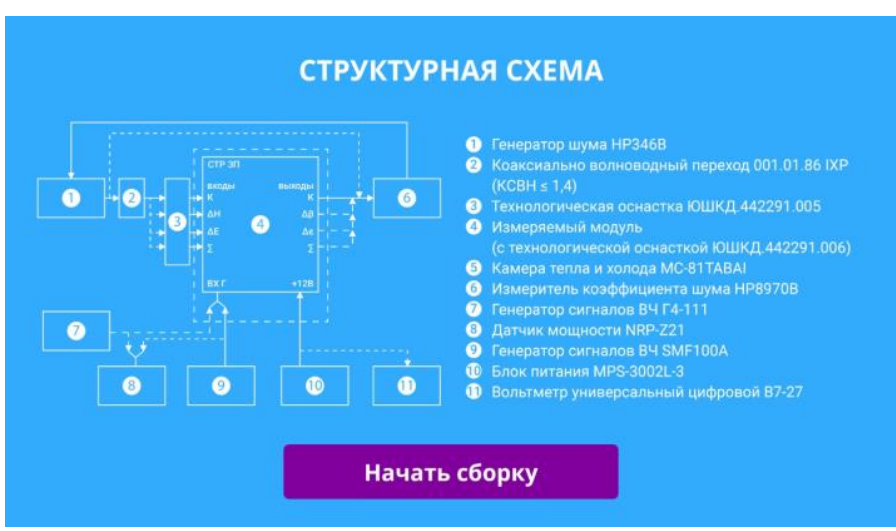

Fig. 7. Structural scheme

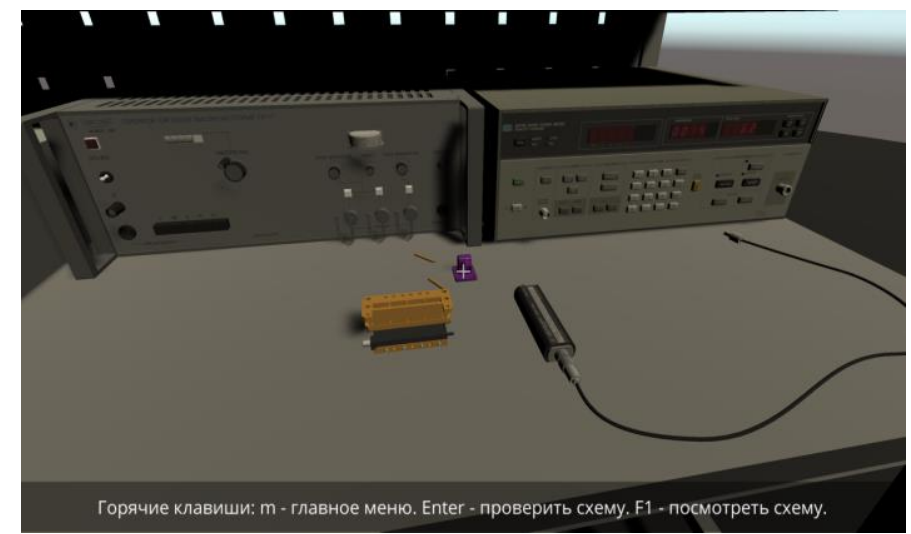

Fig. 8. The scene of build 


\section{Conclusion}

Thus, in this article, the main stages of the development of various forms of presentation of educational materials and their features were identified.

Text instruction is the least visual way of presenting information. It lacks an abundance of visual content, no sound information can be added to it, and there is no interactivity. The advantage of this type of instruction is highest development speed. You needn't to develop additional visual (illustrations, 3d-models, animations) or audio content.

A graphic instruction contains more visual content than a text instruction, but it lacks the ability to add sound and interactivity. The development time is longer, due to the need to develop graphics that illustrate the described processes.

In the multimedia video, in addition to the rich visual design (including the use of $3 \mathrm{~d}$ models), it becomes possible to add sound information, but there is still no interactivity. The duration of development increases significantly due to the need to develop virtual models for the best visualization of the described processes.

The interactive multimedia video contains all 3 components that will allow audial, visual and kinesthetics to perceive information: visual component, audio and interactivity. The duration and complexity of development increases, due to the need to write program code to organize interaction between individual semantic blocks.

The interactive simulator allows the user to be maximally involved in the learning process, contains an abundance of visual and audio information, as well as interactivity. Simulator is great for practicing and testing practical skills. The duration and complexity of development is the highest, due to the need to develop virtual models, write program code and think over the user interface.

The developed training materials help to improve the quality of knowledge of the employee of the enterprise, therefore, allow:

- to increase the speed of mastering new equipment by personnel;

- to increase the speed of work on this equipment;

- to reduce the number of errors made by staff when working with equipment.

The development of this project is provided with the use of mixed reality, which will allow students to fully immerse themselves in the working environment [13, 14]. But at this stage, there is little interest in these technologies at manufacturing enterprises, due to their relative novelty, expensive equipment, specific operation and high cost of content development.

\section{References}

1. Basmanova Y.I., Filinskikh A.D. Khvoinov V.N.: Development of a corporate information system for interaction with users at the enterprise of the state corporation "ROSATOM" FSUE FRPC NIIIS n.a. Y.E. SEDAKOV // Bulletin of the Belgorod State Technological University n.a. V.G. Shukhov. 2017. No. 5. P. 139-143.

2. Filinskih A.D., Merzlyakov I.N.: Project data management. Nizhny Novgorod, 2017. 
10 T. Fedorova, A. Filinskih, O. Sosnina

3. Peskova O.V.: About information visualization // Engineering journal: science and innovations, 2012.

4. Types and methods of information perception, https://fb.ru/article/187059/tipyi-i-sposobyivospriyatiya-informatsii. Last accessed 29062020.

5. How to determine the types of information perception? http://razvitie-intellecta.ru/vizual-audial-kinestet-i-digital-kak/. Last accessed 29062020.

6. Raikin L.I., Subbotina M.N.: On the preparation of content for interactive electronic technical manuals", Proceedings of NSTU n.a. R.E. Alekseev, № 3.

7. Sosnina O.A., Filinskih A.D., Korotaeva A.S.: Comparison of ways to create a low-poly 3D model // Information technologies №8. Volume 23. 2017. - pp. 564-568.

8. Fedorova, T.O., Sosnina O.A.: Stages of developing a virtual model of an architectural structure, consisting of a large number of objects // COGRAF-2019: collection of materials of the 29th All-Russian Scientific and Practical Conference on Graphic Information Technologies and Systems / Nizhny Novgorod. State technical university n.a. R.E. Alekseev. - Nizhny Novgorod, 2019. - 218p.

9. Fedorova, T.O., Sosnina O.A.: Optimization of the duration of rendering scenes with Mental Ray / Information technology №10. Volume 25.2019. - pp. 596-601

10. Sosnina O.A., Filinskih A.D., Lozhkina N.A.: Analysis of methods for creating virtual models of non-trivial forms // Information Technologies. 2019. Vol. 25, № 11, pp. 679-681.

11. Sosnina O.A., Filinskih A.D., Korotaeva A.S.: Comparison of ways to create a low-poly 3D model // Information Technologies. 2017. Vol. 23, № 8, pp. 564-568.

12. Filinskih A.D., Korsakov K. S.: An interactive three-dimensional model of the Nizhny Novgorod Kremlin // Information Technologies. 2018. Vol. 24, № 9, pp. 582-585.

13. Shaposhnikova M.O., Tomchinskaya T.N.: Application of virtual reality technology for training novice drivers // COGRAF-2019. Collection of materials of the 29th All-Russian Scientific and Practical Conference on Graphic Information Technologies and Systems. 2019. pp. 208-212.

14. Dmitriev D.A., Filinskih A.D.: Research of xr-technologies in the educational process // COGRAF-2019. Collection of materials of the 29th All-Russian Scientific and Practical Conference on Graphic Information Technologies and Systems. 2019. pp. 326-330. 